
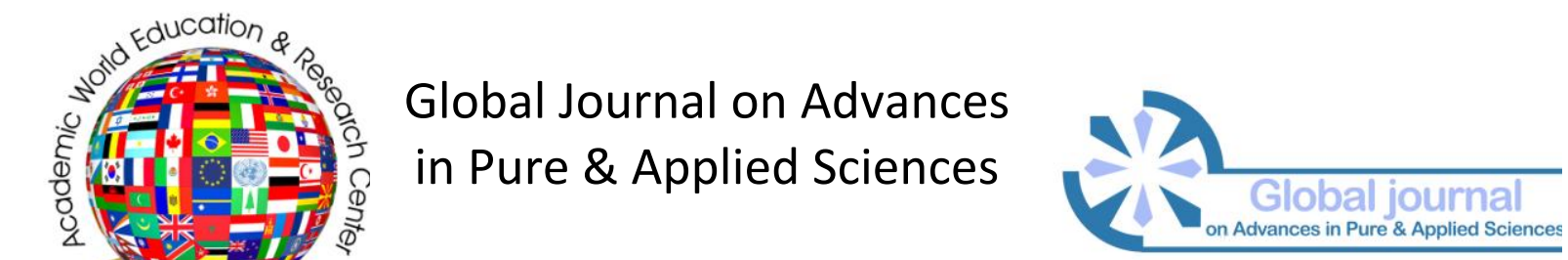

Issue 7 (2016) 13-20

Selected Paper of 2nd World Conference on Health Sciences (H-SCl 2015)

30 April-02 May 2015 Efes Sürmeli Hotel \& Convention Center - İzmir, Kuşadası, Turkey

\title{
Assessment of air pollution effects in the subjects of Khartoum industrial area, Sudan via cytological interpretations
}

Osman EM *, Department of Medical Laboratories Science, Al-Ghad International Colleges for Health Sciences, KSA.

Rahmani AH, Department of Medical laboratory science, College of Applied Medical Sciences, Qassim University, KSA.

Babiker AY, Department of Histopathology and Cytology, College of Medical Laboratories Science, University for Sciences and Technology, Sudan

Moammed Abbass, Department of Medical laboratory science, College of Applied Medical Sciences, Salman bin Abdulaziz University of Al Kharj, KSA.

Abdulwahab Abuderman, Department of Physiology, College of Medicine, Salman bin Abdulaziz University, Kharj -Saudi Arabia.

Alsammani MA, Department of Obstetrics and Gynaecology, College of Medicine, Qassim University, KSA.

Ahmad HG, Department of Pathology, College of Medicine, University of Hail, KSA.

\section{Suggested Citation:}

Osman, E., M., Rahmani, A., H., Babiker, A., Y., Abbass, M., Abuderman, A., Alsammani, M., A. \& Ahmad, H., G. (2016). Assessment of air pollution effects in the subjects of Khartoum industrial area, Sudan via cytological interpretations, Global Journal on Advances in Pure \& Applied Sciences. [Online]. 07, pp 13-20. Available from: $\underline{w w w}$.propaas.eu

Received October 20, 2014; revised January 10, 2015; accepted March 19, 2015.

Selection and peer review under responsibility of Prof. Dr. Fahrettin Sadikoglu, Near East University.

(C)2016 Academic World Education \& Research Center. All rights reserved.

\begin{abstract}
The study was conducted to assess the air pollution-related lung cellular proliferative activity and inflammatory cells infiltrate among Sudanese subjects, who worked at least 8 hours per day. A total of seventy-five workers who worked for at least 5 years in the polluted area were included, sputum/ blood samples were collected to evaluate the cytological atypia and metaplasia.

Out of 75 subjects, Cytological atypia and metaplasia were detected among $8 \%$ and $16 \%$ of the participant respectively, and such types of changes due to the exposure of occupational air pollution were found to be
\end{abstract}

* ADDRESS FOR CORRESPONDENCE: Osman EM, Department of Medical Laboratories Science, Al-Ghad International Colleges for Health Sciences, KSA. E-mail address: myamya88@hotmail.com 
Osman, E., M., Rahmani, A., H., Babiker, A., Y., Abbass, M., Abuderman, A., Alsammani, M., A. \& Ahmad, H., G. (2016). Assessment of air pollution effects in the subjects of Khartoum industrial area, Sudan via cytological interpretations, Global Journal on Advances in Pure \& Applied Sciences. [Online]. 07, pp 13-20. Available from: www.propaas.eu

statistically significant $(P=0.01)$. Similarly, acute and chronic inflammatory cells infiltrate were identified among $10.7 \%$ and $14.7 \%$ of the study subject respectively; the changes was statistically significant compared to control $(P=0.001)$. Exposure to occupational air pollutant was associated with alteration in cells of lungs such atypia, acute and chronic inflammatory cells. This finding supports the earlier studies that long exposure to air pollutants is associated to lung atypical alterations.

Keywords: Lung epithelial, air pollution hazards, Sudan.

\section{Introduction}

Lung cancer is one of the commonest cancers worldwide mainly due to tobacco exposure [1]. The estimated new lung and bronchus cancer cases in United State, 2014 were 224,210 accounting for about $13 \%$ of all cancer diagnoses [2]. In the Arab World, the uppermost mortality rates due to lung cancer were estimated in the Northern African Arab (Egypt (20.7\%), Morocco (20.4\%), Algeria (15.4\%) and then Tunisia (9.9\%) of the total death). $83.3 \%$ of a total deaths related to lung cancer in the Arab populations were in males [3]. Since Sudan has no national population-based cancer registry, the only sources of lung cancer data are the hospital-based case series and researches. The relative frequency of lung cancer in the reported case series of adult Sudanese was $0.5 \%[4,10]$. Lung was not one of the 10 top common cancer site in a study conducted in Khartoum, Sudan between 2009 -2010, the estimated number of incident lung cancer cases was 159 using the Age-standardized rate (ASR) and Khartoum 2009 [11]

Various factors play an important role in the development and progression of lung cancer including cigarette smoking, chewing, and genetic alterations $[12,14]$. Air pollution is one of the main players in development of lung cancer via alteration in the genes/DNA damage. Previous studies have reported an increase lung cancer among workers exposed to constituents of urban air pollution including polycyclic aromatic hydrocarbons and diesel exhaust $[15,16]$. Unfortunately, the exact mechanism of air pollutants in cancer development is not understood completely. It was considered that constituents of air pollution bind to DNA and causes DNA adduct and finally cancer development occurs. Air pollutant or particulate matter also causes inflammation/asthma and reduced lung function. Earlier studies have shown that outdoor air pollution is associated with decreased lung function $[17,18]$. Pollution and smoking can also cause cell death by necrosis, and with the process of apoptosis, which can increase inflammatory strength [19]. The current study aimed to assess the relationship between air pollution exposure and lung inflammatory processes and alteration in lung cell in the exposed subjects.

\section{Materials and Methods}

A total of seventy five participants from Khartoum industrial area, Sudan who worked for at least the latest 8 hours a day for 5 years or more were investigated for lung cellular and inflammatory changes. The workers who worked for one year or less considered as control. Sputum and blood sample were collected and processed for cytological examination. $5 \mathrm{ml}$ of venous blood was taken in EDTA container for differential blood count by using Sysmix haematology analyser (K21). A questionnaire was used to collect demographical data. Each participant was asked to sign ethical consent and ethical consent form was designed and accepted by the ethical committee of Faculty Research Board, FMLS, and Sudan Academy of sciences (SAS).

Sample Processing for cytological examination: Sputum with deep cough was collected in the early morning and the smear was made. The Smears were further treated according to Papanicolaou method [20]. For nuclear and cytoplasmic staining, smears were treated with Harris's Haematoxylin 
Osman, E., M., Rahmani, A., H., Babiker, A., Y., Abbass, M., Abuderman, A., Alsammani, M., A. \& Ahmad, H., G. (2016). Assessment of air pollution effects in the subjects of Khartoum industrial area, Sudan via cytological interpretations, Global Journal on Advances in Pure \& Applied Sciences. [Online]. 07, pp 13-20. Available from: www.propaas.eu

and Papanicolaou Orange G6 solution respectively. Another smear were stained using silver nitrate method for Ag NOR protein sites and mounted with DPX medium and analysis were made.

Cytological assessment of the epithelial atypia: Nuclear enlargement, changed nuclear/cytoplasmic ratio, nuclear hyperchromatism, irregularity of nuclear membranes was calculated.

Statistical analysis: Statistical Package for Social Sciences (version 16) was used for the analysis and to perform Chi-square test for statistical significance ( $P$ value).

\section{Results}

A total 75 participants with ages ranging from 20 to 71 years (mean= 29.5 years) were selected. Most of the cases were between $20-30$ years representing $42.7 \%$ of the study subjects. The cytological atypia and metaplasia were detected in $6 / 75(8 \%)$ and $12 / 75(16 \%)$ of the targets respectively and these changes were found to be statistically significant $(P=0.01)$ (Table 1$)$ [Figure $1,2,3$ and 4]. Furthermore, acute and chronic inflammatory cells infiltrate were identified among $8 / 75(10.7 \%)$ and $11 / 75(14.7 \%)$ subjects (Figure 4) and chest diseases were observed among 5/75 (6.7\%).

Table1. Distribution of cases by cytological findings Data presented as number (percentage)

\begin{tabular}{llll}
\hline Variable & $\begin{array}{l}\text { Present } \\
\text { Yes }\end{array}$ & Absent & $P$ Value \\
& & No & \\
\hline Atypia & $6(8)$ & $69(92)$ & 0.01 \\
Metaplasia & $12(16)$ & $63(84)$ & 0.0001 \\
Acute Inflammation & $8(11)$ & $67(89)$ & 0.001 \\
Chronic Inflammation & $11(15)$ & $64(85)$ & 0.0001 \\
Chest Disease & $5(7)$ & $70(93)$ & 0.01 \\
\hline
\end{tabular}

Data presented as number (percentage)

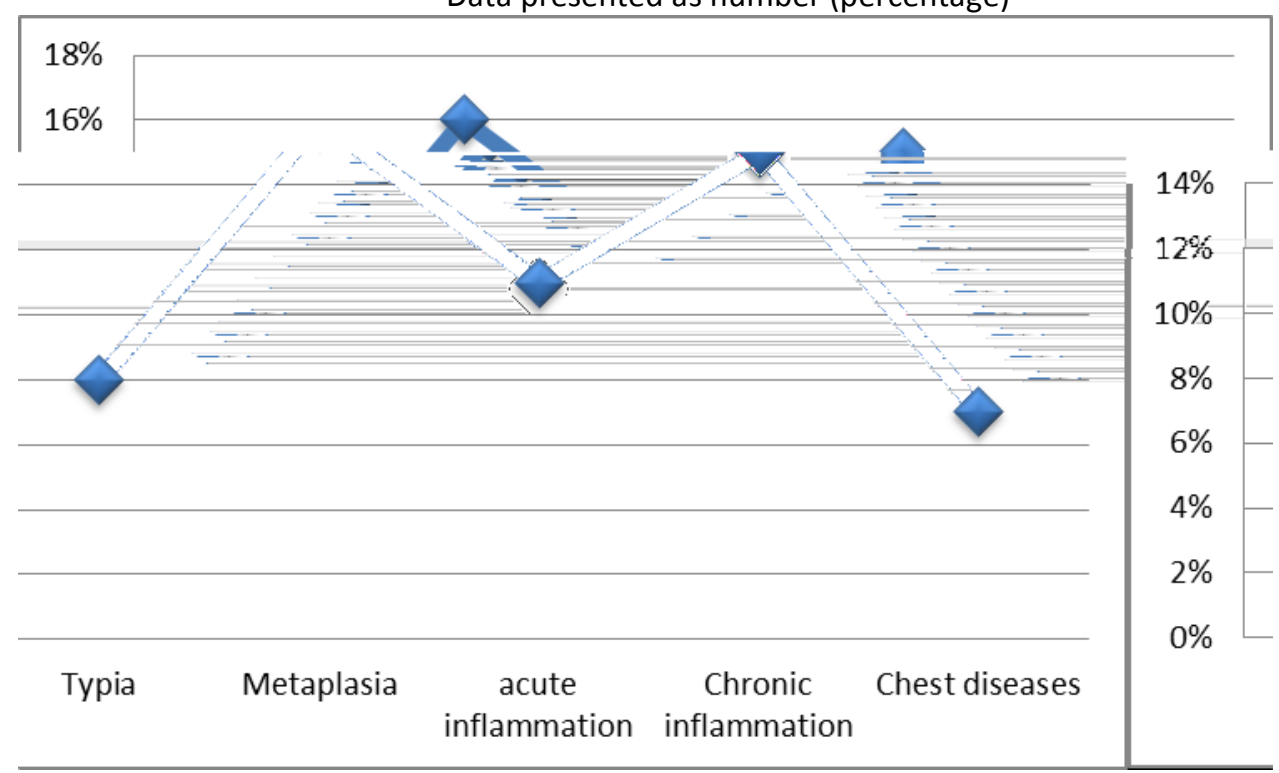

Figure. 1 Description of the study subjects by cytological findings 
Osman, E., M., Rahmani, A., H., Babiker, A., Y., Abbass, M., Abuderman, A., Alsammani, M., A. \& Ahmad, H., G. (2016). Assessment of air pollution effects in the subjects of Khartoum industrial area, Sudan via cytological interpretations, Global Journal on Advances in Pure \& Applied Sciences. [Online]. 07, pp 13-20. Available from: www.propaas.eu

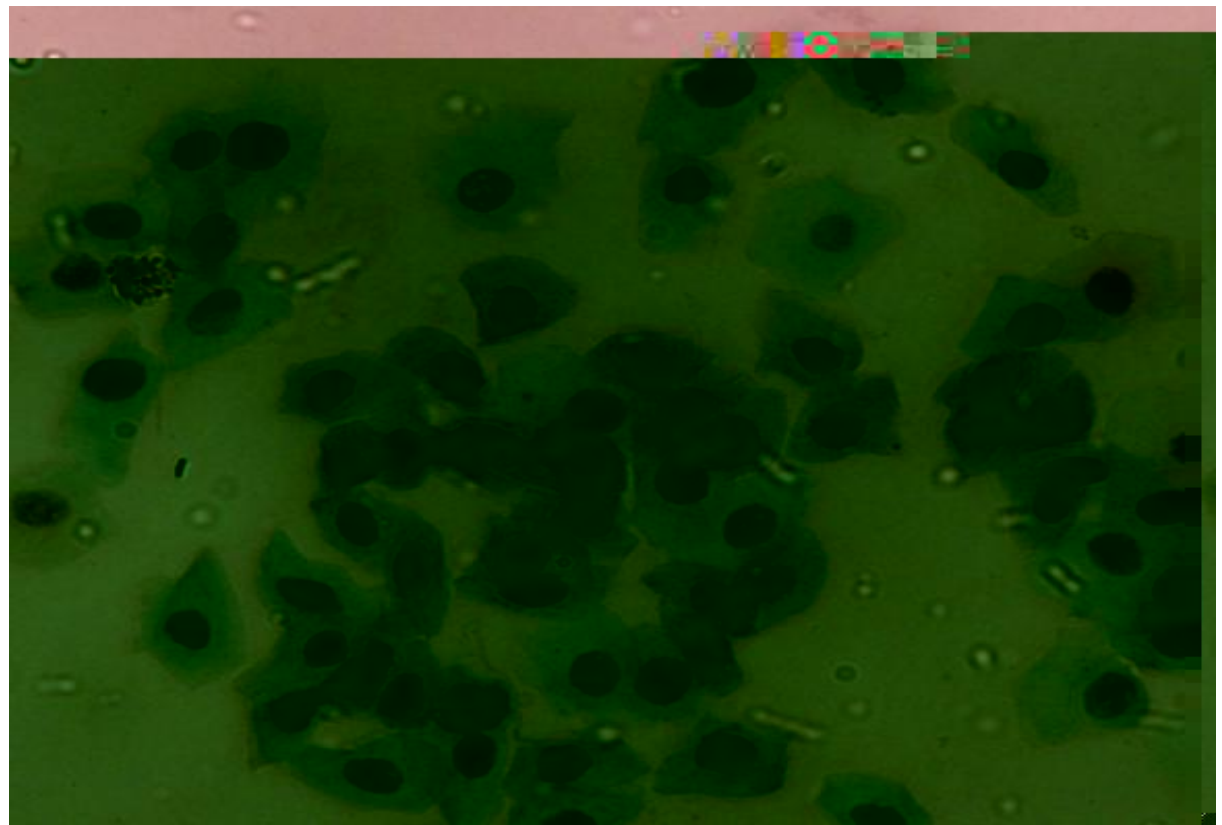

Figure 2. Sputum specimen showing epithelium cells with metaplasia. Pap. Stain X40.

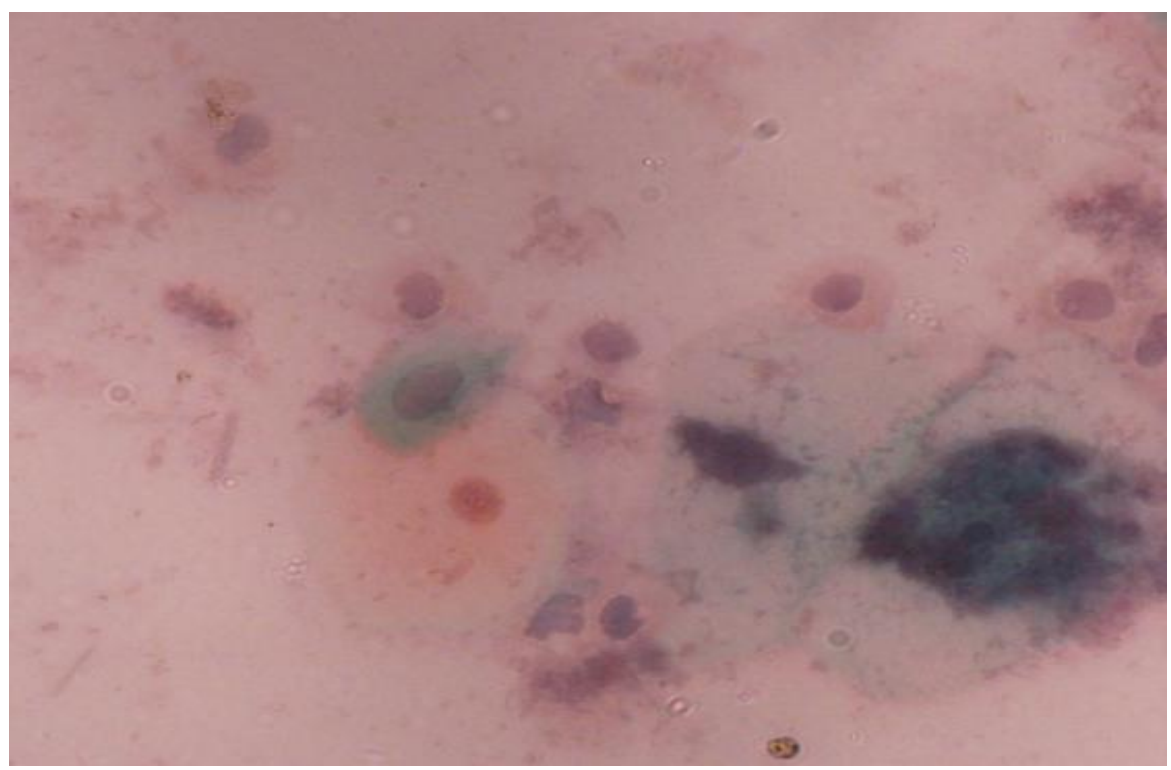

Figure 3. Sputum specimen showing epithelium cells with metaplasia. Pap. Stain X40. 
Osman, E., M., Rahmani, A., H., Babiker, A., Y., Abbass, M., Abuderman, A., Alsammani, M., A. \& Ahmad, H., G. (2016). Assessment of air pollution effects in the subjects of Khartoum industrial area, Sudan via cytological interpretations, Global Journal on Advances in Pure \& Applied Sciences. [Online]. 07, pp 13-20. Available from: www.propaas.eu

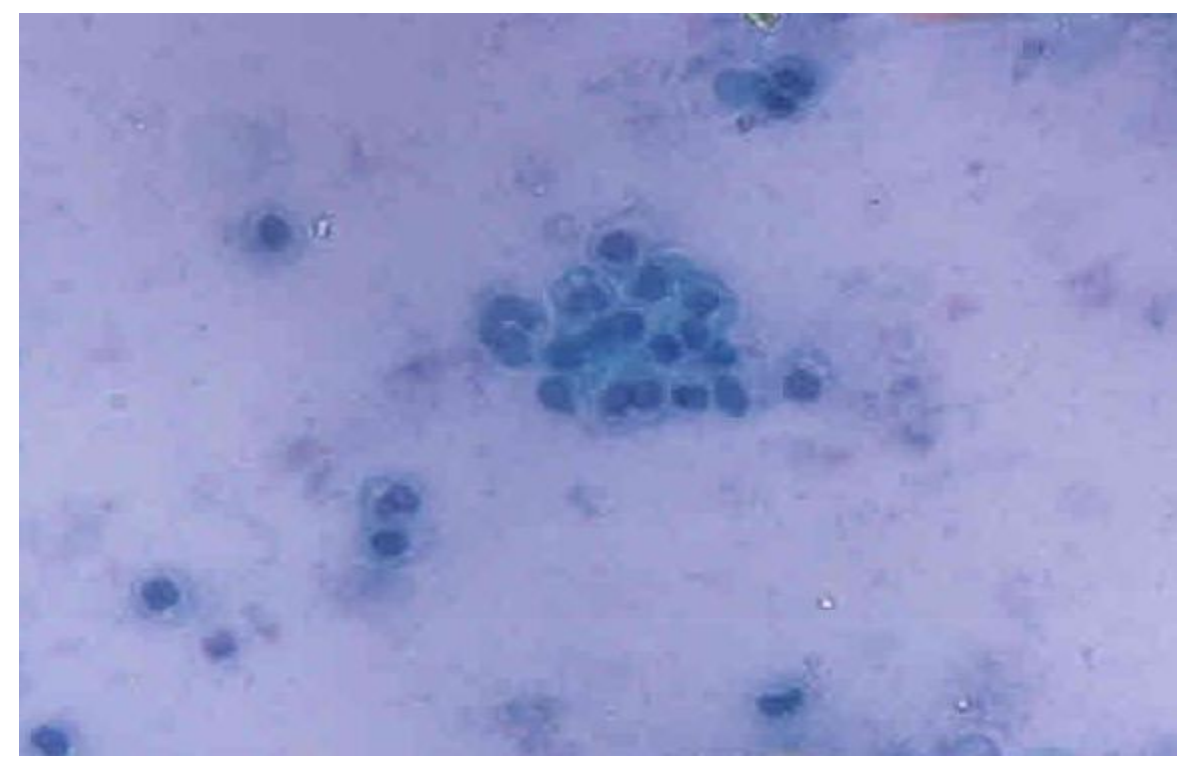

Figure 4. Sputum specimen showing epithelium cells with atypia. Pap. Stain X40.

High TWBCs counts were observed among 1/ 6(16.7\%), 5/12 (41.7\%), 5/8(62.5\%), 4/11 (36.4\%) and $2 / 5(40 \%)$ of the atypia, metaplasia, acute inflammation, chronic inflammation and chest diseases, respectively (Table 2 ) (Figure 5 ).

Table 2. Distribution of cases by levels of TWBCS

\begin{tabular}{lccccc}
\hline \multirow{2}{*}{ Variable } & & \multicolumn{3}{c}{ TWBCs } & Total \\
\hline Atypia & Category & $<4000$ & $4000-7000$ & $>7000$ & 6 \\
& Yes & 0 & 5 & 1 & 69 \\
Metaplasia & No & 20 & 30 & 19 & 12 \\
& Yes & 2 & 5 & 5 & 63 \\
Acute & No & 18 & 30 & 15 & 8 \\
Inflammation & Yes & 0 & 3 & 5 & 67 \\
Chronic & No & 20 & 32 & 15 & 11 \\
Inflammation & Yes & 3 & 4 & 4 & 64 \\
Chest Disease & No & 17 & 31 & 16 & 5 \\
& Yes & 1 & 2 & 2 & 70 \\
\hline
\end{tabular}


Osman, E., M., Rahmani, A., H., Babiker, A., Y., Abbass, M., Abuderman, A., Alsammani, M., A. \& Ahmad, H., G. (2016). Assessment of air pollution effects in the subjects of Khartoum industrial area, Sudan via cytological interpretations, Global Journal on Advances in Pure \& Applied Sciences. [Online]. 07, pp 13-20. Available from: www.propaas.eu

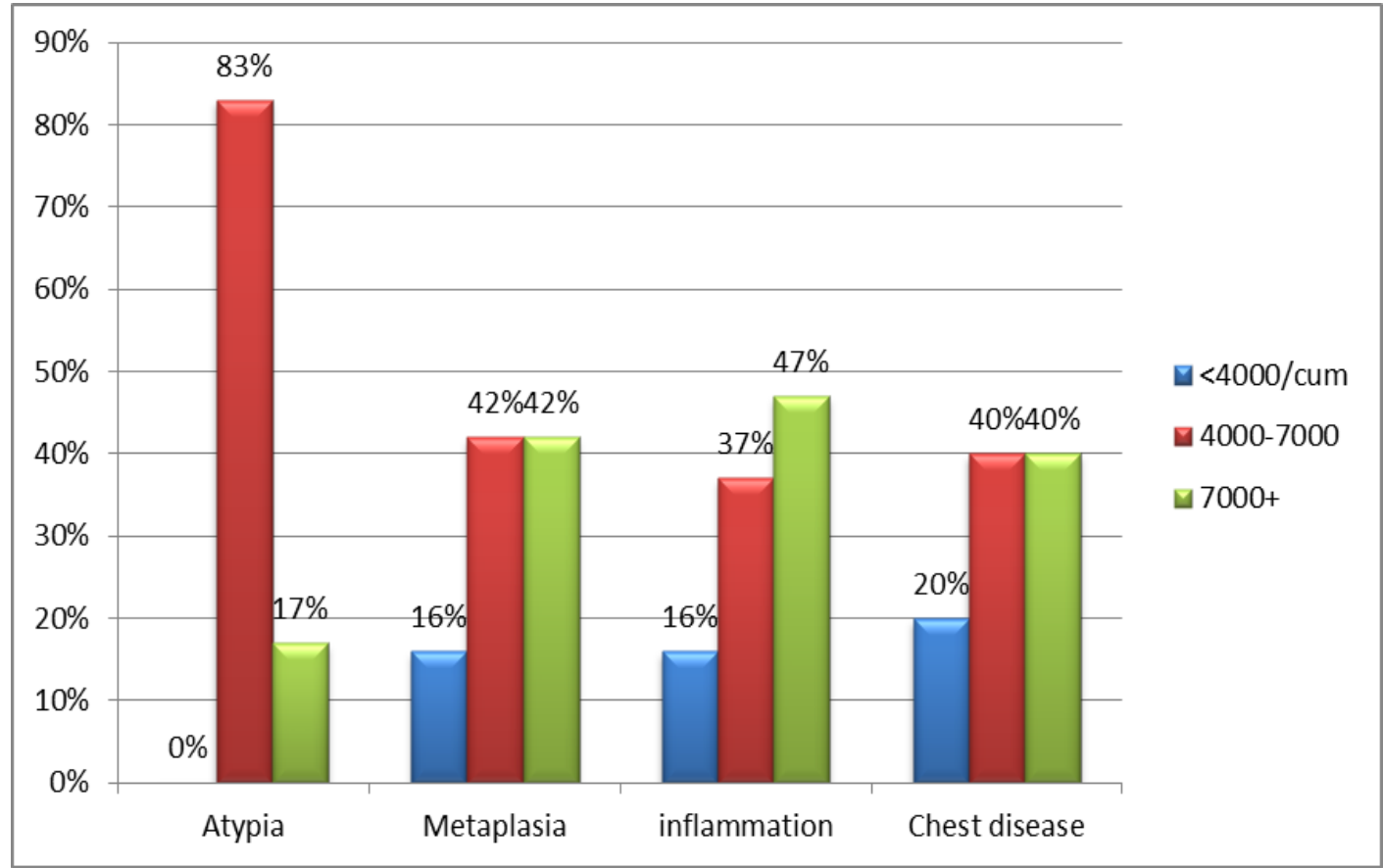

Figure 5. Description of the TWBCs count by cytological findings

Cytological atypia was categorized according to occupation and it was found that $3 / 6(50 \%), 2 / 6$ (33.3\%), and $1 / 6(16.7 \%)$ of the blacksmith, mechanic and painters showed cytological atypia respectively. Additionally, metaplasia was also detected among 5/51(9.8\%), 4/17(23.5\%) and $3 / 3(100 \%)$ of the mechanic, blacksmith and painter.

Acute and chronic inflammatory cells infiltrate was demonstrated according to occupation. It was observed that acute inflammatory cells infiltrate was 5/51(9.8\%) in mechanic, $2 / 17(11.8 \%)$ in blacksmith and $1 / 4(25 \%)$ in managers. Chronic inflammatory cells infiltrate was demonstrated in $6 / 51(11.8 \%), 3 / 17(17.7 \%), 1 / 4(25 \%)$ and $1 / 3(33.3 \%)$ of the mechanic, blacksmith, managers and painters respectively.

\section{Discussion}

The effect of air pollution on the expose subject was analyzed by cytological methods and total white blood cells count (TWBCs) was measured in various air pollutant exposed subjects. In our study an association between air pollution, lung atypia and metaplasia was noticed. Previous finding has shown that stronger associations between traffic-related air pollution and lung metaplasia and the relative risk increases with cigarette smoking [21]. The exact cause of dysplasia, lung atypia and metaplasia is not known exactly but it is considered that various factor responsible for the alteration in lung cells including air pollutants. Air pollutants also cause respiratory disordered such as asthma and other respiratory related complications. Earlier epidemiological studies have shown an association between exposure to motor vehicle traffic emission and allergic symptoms and reduced lung function [22].

Our study also observed Inflammatory infiltrate in a considerable number in exposed subjects. The possible reason of inflammatory infiltrate in lung is due to the body defence system, which plays an important role in the production of inflammatory response against foreign particle such as dust, 
Osman, E., M., Rahmani, A., H., Babiker, A., Y., Abbass, M., Abuderman, A., Alsammani, M., A. \& Ahmad, H., G. (2016). Assessment of air pollution effects in the subjects of Khartoum industrial area, Sudan via cytological interpretations, Global Journal on Advances in Pure \& Applied Sciences. [Online]. 07, pp 13-20. Available from: www.propaas.eu

pollutant and particulates. Several studies have confirmed the pollutants shows an important role in increases of neutrophils or eosinophils. Earlier study has revealed that traffic policemen showed a statistically significant increase in the percentage neutrophil cell count as compared to the Healthy Subjects [23]. Another study results showed that patients living within $1000 \mathrm{~m}$ of highways showed an increased risk of bronchitis and increased risk of an asthma diagnosis [24].

In our finding results confirm that considerable number of subjects has symptoms such acute and chronic inflammation and chest diseases. On the other side, significant number of subjects also showed low total WBC count. The exact explanation in this issue is not achieved but it is hypothesized that subject exposed with air pollutant for long time especially who worked at least 8 hours per day for several years shows weak immunity and also shows other complications such chest diseases and chest tightness. Previous finding showed that a variety of inhaled materials stimulate alveolar macrophages to produce proinflammatory cytokines including IL-1, IL-6, and IL-8 and TNF- $\alpha$ [25, 28].

\section{Conclusion}

Our results indicated an association of long term exposure of air pollutant and lung cell alterations such atypia and metaplasia and air pollution might lead to causes acute and chronic inflammation. Additionally, long term exposure also causes changes in WBC count and finally altered the immune response.

\section{Acknowledgement}

The authors sincerely thank all who participate in this work.

\section{Conflict of interest}

There was no conflict of interest.

\section{References}

[1] Parkin, D. M., Bray, F., Ferlay, J., \& Pisani, P. (2005). Global cancer statistics, 2002. CA: a cancer journal for clinicians, 55(2), 74-108.

[2] Siegel, R., Ma, J., Zou, Z., \& Jemal, A. (2014). Cancer statistics, 2014. CA: a cancer journal for clinicians, 64(1), 9-29.

[3] Salim, E. I., Jazieh, A. R., \& Moore, M. A. (2011). Lung Cancer incidence in the Arab league countries: Risk Factors and Control. Asian Pac J Cancer Prev,12, 17-34.

[4] Hickey, B. B. (1959). Malignant Epithelial Tumours in the Sudanese: Hunterian Lecture delivered at the Royal College of Surgeons of England on 13th March 1958. Annals of the Royal College of Surgeons of England, 24(5), 303.

[5] Hamad, H. M. A. (2006). Cancer initiatives in Sudan. Annals of oncology,17(suppl 8), viii32-viii36.

[6] Daoud, E. H., El Hassan, A. M., Zak, F., \& Zakova, N. (1968). Aspects of malignant disease in the Sudan. Cancer in Africa. Nairobi: East African Publishing House, 43-50.

[7] Malik, M. O. A., El Din, Z. A., \& El Masri, S. H. (1976). Cancer of the alimentary tract in the Sudan. A study of 546 cases. Cancer, 37(5), 2533-2542.

[8] Hidayatalla, A., \& Rahman, E. A. (1986). The Radiation and Isotope Centre, Khartoum, 1967-1984. Parkin DM. Cancer occurrence in developing countries ed. Lyon: IARC, 82-7.

[9] Mukhtar, B. I. (1986). The Sudan Cancer Registry, 1978. Cancer occurrence in developing countries, IARC press, Lyon, 81-85. 
Osman, E., M., Rahmani, A., H., Babiker, A., Y., Abbass, M., Abuderman, A., Alsammani, M., A. \& Ahmad, H., G. (2016). Assessment of air pollution effects in the subjects of Khartoum industrial area, Sudan via cytological interpretations, Global Journal on Advances in Pure \& Applied Sciences. [Online]. 07, pp 13-20. Available from: www.propaas.eu

[10] Ageek, A. K., Ali, B. M., \& Awadelkarim, M. A. (2007). Pattern and incidence of cancer in Red Sea State, Sudan. Sudan J Med Sci, 2, 115-9.

[11] Saeed, I. E., Weng, H. Y., Mohamed, K. H., \& Mohammed, S. I. (2014). Cancer incidence in Khartoum, Sudan: first results from the Cancer Registry, 2009-2010. Cancer medicine, 3(4), 1075-1084.

[12] Schuller, H. M., Tithof, P. K., Williams, M., \& Plummer, H. (1999). The tobacco-specific carcinogen 4(methylnitrosamino)-1-(3-pyridyl)-1-butanone is a $\beta$-adrenergic agonist and stimulates DNA synthesis in lung adenocarcinoma via $\beta$-adrenergic receptor-mediated release of arachidonic acid. Cancer Research,59(18), 4510-4515.

[13] Hecht, S. S. (2012). Lung carcinogenesis by tobacco smoke. International journal of cancer, 131(12), 27242732.

[14] Rahmani, A., Alzohairy, M., Babiker, A. Y., Rizvi, M. A., \& Elkarimahmad, H. G. (2012). Clinicopathological significance of PTEN and bcl2 expressions in oral squamous cell carcinoma. International journal of clinical and experimental pathology, 5(9), 965-971

[15] Boffetta, P., Jourenkova, N., \& Gustavsson, P. (1997). Cancer risk from occupational and environmental exposure to polycyclic aromatic hydrocarbons. Cancer Causes \& Control, 8(3), 444-472.

[16] Lipsett, M., \& Campleman, S. (1999). Occupational exposure to diesel exhaust and lung cancer: a metaanalysis. American journal of public health, 89(7), 1009-1017.

[17] Linaker, C. H., Coggon, D., Holgate, S. T., Clough, J., Josephs, L., Chauhan, A. J., \& Inskip, H. M. (2000). Personal exposure to nitrogen dioxide and risk of airflow obstruction in asthmatic children with upper respiratory infection. Thorax, 55(11), 930-933.

[18] James Gauderman, W., McConnell, R. O. B., Gilliland, F., London, S., Thomas, D., Avol, E., ... \& Peters, J. (2000). Association between air pollution and lung function growth in southern California children. American journal of respiratory and critical care medicine, 162(4), 1383-1390.

[19] Alfaro-Moreno E, Martínez L, García-Cuellar C, Bonner JC, Murray JC, Rosas I, Rosales SP, Osornio-Vargas ARBiologic effects induced in vitro by PM10 from three different zones of Mexico City. Environ Health Perspect. 2002;110:715-20.

[20] John, D., \& Bancroft, A. S. (1996). Theory and practice of histological techniques. None translator.

[21] Ahmed, H. G., \& Rezgalla, T. M. (2010). A Study of lung epithelial atypia in regard to the effect of smoking and traffic-related Air pollution in Sudan. The Open Lung Cancer Journal, 3, 1-6.

[22] Heinrich, J., \& Wichmann, H. E. (2004). Traffic related pollutants in Europe and their effect on allergic disease. Current opinion in allergy and clinical immunology, 4(5), 341-348.

[23] Dragonieri, S., Musti, M., Izzo, C., Esposito, L. M., Barbaro, M. P. F., Resta, O., \& Spanevello, A. (2006). Sputum induced cellularity in a group of traffic policemen. Science of the total environment, 367(1), 433-436.

[24] Wallace, J., D’silva, L., Brannan, J., Hargreave, F. E., Kanaroglou, P., \& Nair, P. (2011). Association between proximity to major roads and sputum cell counts. Canadian respiratory journal: journal of the Canadian Thoracic Society, 18(1), 13.

[25] Mukae, H., Hogg, J. C., English, D., Vincent, R., \& Van Eeden, S. F. (2000). Phagocytosis of particulate air pollutants by human alveolar macrophages stimulates the bone marrow. American Journal of Physiology-Lung Cellular and Molecular Physiology, 279(5), L924-L931.

[26] Terashima, T., Wiggs, B., English, D., Hogg, J. C., \& van EEDEN, S. F. (1997). Phagocytosis of small carbon particles (PM10) by alveolar macrophages stimulates the release of polymorphonuclear leukocytes from bone marrow. American journal of respiratory and critical care medicine, 155(4), 1441-1447.

[27] Terashima, T., Klut, M. E., English, D., Hards, J., Hogg, J. C., \& Van Eeden, S. F. (1999). Cigarette smoking causes sequestration of polymorphonuclear leukocytes released from the bone marrow in lung microvessels. American journal of respiratory cell and molecular biology, 20(1), 171-177.

[28] van EEDEN, S. F., Tan, W. C., Suwa, T., Mukae, H., Terashima, T., Fujii, T., ... \& Hogg, J. C. (2001). Cytokines involved in the systemic inflammatory response induced by exposure to particulate matter air pollutants (PM10).American Journal of Respiratory and Critical Care Medicine, 164(5), 826-830. 